\title{
Prefeasibility Analysis of Electric Power Generation from Municipal Solid Waste using RETScreen: A Case Study of Peshawar City
}

\author{
Muhammad Shabir khan ${ }^{1}$, Muhammad Raheel ${ }^{2}$, Muhammad humayun ${ }^{3}$, Muhammad Naeem khan \\ ${ }^{1,2}$ USPCAS-E, University of Engineering \& Technology, Peshawar \\ ${ }^{3,4}$ University of Engineering \& Technology, Peshawar \\ shabiruet555@gmail.com ${ }^{1}$, raheel_khan740@yahoo.com², \\ humayunchemist@nwfpuet.edu.pk ${ }^{3}$, khattak1962@yahoo.com ${ }^{4}$ \\ Received: 15 October, Revised: 20 November, Accepted: 27 December
}

\begin{abstract}
The escalation in the level of municipal solid waste generation by mankind is the index of using natural resources in an unsustainable and ineffective manner while that pattern has continued and paved its way to the exhaustion of the natural resources and environmental changes. Pakistan is not confronted solely by the increase in population growth like the other developing countries but it has also an escalation in its Municipal Solid waste (MSW) generation. The concerned municipal corporation authorities are incapable to cope up with due to a boost in the increased urbanization. Energy from waste being renewable energy can generate a good enough amount of electricity; reduces greenhouse gas emissions, solid waste minimization as well as it's a good source for a circular economy. RETScreen Expert Software support tool has been used in this study to determine the prefeasibility analysis of electricity generation from Peshawar city municipal solid wastes suggesting power plant having capacity assumed to be of $10 \mathrm{MW}$ using city mix municipal solid waste it's being analyzed that for a $10 \mathrm{MW}$ system which can export 74,816 MWh of electricity to the grid and the revenue generation from that will be $11,970,503$ CAD. While the GHG emission reduction would be 32,598 tons of $\mathrm{CO}_{2}$ having a simple payback period of 7.7 years with a cost to benefit ratio of 1.5 hence from the result its recommended to have a waste to energy facility for the Peshawar city municipal solid waste.
\end{abstract}

Keywords - RETScreen, waste to energy, incineration, Landfill gas to energy, Solid waste in Peshawar

\section{INTRODUCTION}

The significant intense growth in worldwide population is linked with the economic growth which is headed to swift urbanization as well as industrialization, this concerned situation of the population altered the pattern of consumption of goods which eventually at the end of the day it direct to the propagation of municipal solid waste at an upsetting degree [1].The study by the World Bank approximates that currently nearly 1.3 billion tonnes of MSW are produced every year around the world or $1.2 \mathrm{~kg} /$ capita/day. The exactly actual per capita rates however, vary highly as there are enormous diversities in the waste generation rates across the countries, between cities and even within the cities and localities [2]. by 2025 this amount will reach to 2.2 billion tonnes per year which represents the substantial escalation in the per capita waste generation rates from $1.2 \mathrm{~kg}$ to $1.42 \mathrm{~kg} / \mathrm{person} /$ day in the coming next fifteen years [3] several techniques and practices are in operation around the world to generate energy and utilize the MSW in environmental and cost-effective manner such as landfill gas to energy, to make a compost out of it, electric power generation from MSW by incineration, pyrolysis, and plasma gasification, etc. [4]

\section{CURRENT Municipal SOILD WASTE SituATION IN PAKISTAN}

Pakistan is not confronted solely by the increase in population growth like the other developing countries however it has likewise an escalation in its generation of MSW. The concerned corporation authorities who deal with municipal solid wastes are incapable to cope up with due to a boost in the increased urbanization. In the season of monsoon, the issues of managing the waste worsen to that level that the big city ceases because the drainage gets jammed, blocked sewers system and standing effluent ponds.

Pakistan is in the list of the world densest and congested countries but still, date in any big cities of the country here is no appropriate management system for solid waste exists. The major and the most vital discarding process for MSW in the country has been open- landfilling and open-air dumping for several decades, though after agreeing and complying in 2005 with the Kyoto Protocol, Pakistan has anticipated and planned several projects over Clean development mechanism CDM in order to shrink its way of landfilling their MSW however still one can observe that these initiatives are not so far driven in the region as compared to its nearby countries due to absence of interest by the provincial and federal governments, funds, expertise and by the public as well.

The solid waste per day generation in Pakistan according to an approximates is almost 67,500 tonnes in which the probably waste picked would be only 50-69 \% and these picked and collected mix waste has been sent to open dumps and landfills 
areas usually located on the outside of the cities while the remaining waste left there as it as on the roadsides, in storm drains, open water sewers which pollute water, air and poses serious health concern to the public [5]

\section{i. $\quad$ MSW current mechanism in Peshawar city}

The city of Peshawar is considered one of the big cities of the country almost generates 800-1000 tonnes of solid waste per day whereas $40-50 \%$ gets collected in the unsegregated form and being landfilled in open dumping. There are four different organization working relevant to solid waste collection and disposal i.e. WSSP, TMA, PDA, local council Board.

In the city to date there is no proper segregation, collection and waste to energy setup.

\section{ii. Composition of Peshawar city municipal solid waste}

The Peshawar city municipal solid wastes predominantly comprises of food wastes which usually includes fruits and vegetables, wood, paper products, wood straws, and wood materials (boards, chips, and cardboards), plastics, textiles, rubbers and packing materials of different utility items, etc. Major waste type and its composition being provided in the table [5]

Table I. MSW COMPOSITION OF PESHAWAR CITY [5]

\begin{tabular}{|l|l|}
\hline Type & Waste composition (\%) \\
\hline Fruits and vegetable wastes & 31.9 \\
\hline Plastics & 20.4 \\
\hline Papers & 13.1 \\
\hline Wood straws and tree trimmings & 12.3 \\
\hline Textiles & 8.7 \\
\hline $\begin{array}{l}\text { Leather and rubbers } \\
\text { Non-flammable materials i.e. } \\
\text { clay debris etc. }\end{array}$ & 9.1 \\
\hline
\end{tabular}

\section{LITERATURE REVIEW}

MSW is a term commonly referred as a waste or litter which comprises of different daily practice items usually that are thrown away after usage such items contains furniture's, food scraps, grass clippings, clothing's, bottles, product packaging newspapers, varied appliances while some of the waste such as batteries waste, paints others hazardous and industrial wastes are not measured as MSW.

The global world population grows rapidly and the standard of living of peoples also get rises due to which a huge trends develop in the daily consumption usage of goods and increase in energy utilization as well along with that deforestation and change in the land usage, increase in the agriculture practices, industrialization, and energy usage from conventional fossil fuels sources. Since considering all of these as a whole and their impact have been so large in the immense increase in the potential contribution to ever-increasing levels of greenhouse gases in the atmosphere since the industrial era revolution.

Pakistan is not confronted solely by the increase in population growth like the other developing countries but it has an escalation in its generation of MSW. The concerned municipal corporation authorities are incapable to cope up with due to a boost in the increased urbanization [5].

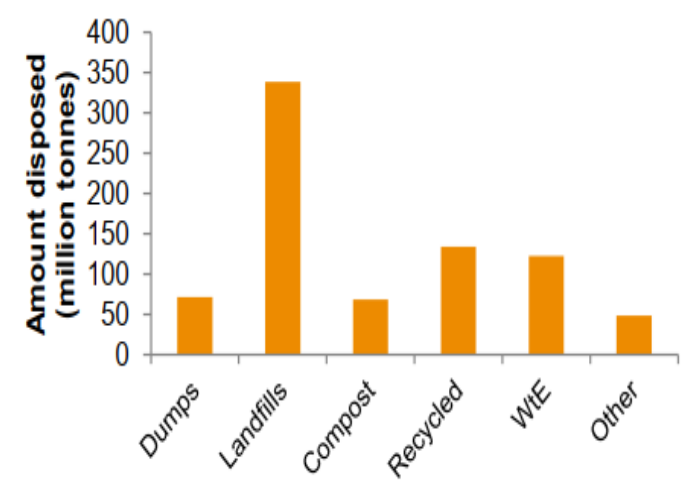

Figure 1: Quantity of waste disposed in 2012 by various processing techniques [9]

Countries like Pakistan which is the world sixth most populous country and its population increases rapidly but usually faces extreme level of energy crisis hence for Pakistan which has many environmental concern and energy issues the concept of electric power generation using waste to energy technology from municipal solid wastes would be a great matter of benefits, the electricity per unit price in Pakistan is almost higher due to a huge significant dependency on imported oil for power generation sectors as in the year 2011 oil import of the country were $40 \%$ of the total imports such sort of situation has led the country trade deficit to $12 \%$ in such circumstances where a country is running out of energy resources, the technology of energy generation from solid wastes which is considered as a renewable resource as well will be a good contribution to the energy mix of the country and can also bring down the energy cost per unit of electricity[6]MSW configuration differs greatly from country to country Depending on weather climate conditions, economic growth, culture, and energy sources utilization, where nation with low income have great portion of organic waste on the contrast MSW of high-income countries are greatly dominant by inorganic part [7].Different countries around the world have opted for and adopted the waste to energy technologies to produce energy, compost, and many useful products from solid waste as well as properly handling, disposing waste in sustainable and effective manner.

An approximation by the IRENA depicts that the world has a huge tremendous prospective of producing almost 1.3 Gigawatts of energy from the waste to the energy sector alone 
[8] In the Fig 1. shown that the quantity of waste disposed/treated in millions of tons with the corresponding various treatment techniques the figure below clearly depicts that Landfilling is most common waste treatment techniques which is basically inefficient, environmentally polluting method.

\section{A. Waste to Energy}

The major and the most important aim of managing solid waste are material handling, collection, and recovering energy monitored by clearance of the residues, In waste processing technology the prime choice is not just to recover energy or waste demolition capacity or economic requirements but it's also to aspect and cater for environmental regulatory compliance of the relevant part that's why it's become mandatory to choose the finest accessible technology for treating wastes which have the tendency to match with the required standard criteria for a successful operation [10]. It's a great matter of concern and necessary to opt for a technology and usually selection of waste to energy technology depends on solid waste feedstock types, its composition, volatile components in the waste, end-use requirement, pollution control standards, economic and specific factors of the projects.

\section{B. Different Energy Recovery Pathways from $M S W$}

Several technologies developed around the globe in order to divert wastes from going to landfills the developing countries are focusing more on the innovation of the biological treatment (Composting) and incineration processes which can fit the MSW composition with high organic content. In order to obtain energy from MSW would greatly lessen solid waste, minimize the usage of conventional fuel which ultimately mitigate $\mathrm{GHG}$ emissions i.e. mitigating $\mathrm{CH} 4$ to $\mathrm{CO} 2$, Presently, in nearly 40 countries greater than 800 thermal WTE plants are functioned globally; which produces up to about a total of $429 \mathrm{TW}$ h of power by treating approximately $11 \%$ of MSW generated worldwide [11]

Different WTE conversion processes exist in which the most important and greatly used processes are, a) thermal conversion which is further divided into incineration, gasification, pyrolysis b) biological conversion in which further it is classified into biomethanation or anaerobic digestion and composting process .c) landfilling with gas recovery [12]. Financial analysis and per kWh of energy generation of various waste treatments from MSW is provided in the Fig 2.

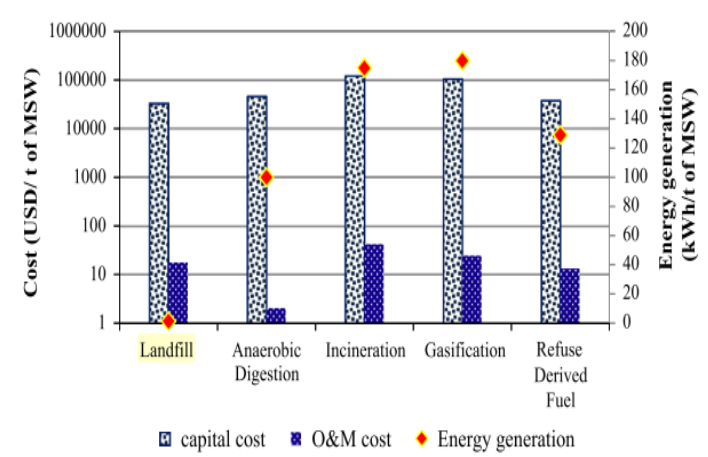

Figure 2: Energy production and financial analysis of WTE technologies [13]

\section{METHODOLOGY}

\section{a) Study area of the Project}

The solid waste generation in the major cities of Pakistan has been trending due to huge urbanization and living standard of people. In this study Peshawar city as shown below in the map the provincial capital of Khyber-Pakhtunkhwa has been selected as a case study, as the city almost generates 800-1000 tonnes of solid wastes per day. RETScreen expert software analysis tool is used to assess the prefeasibility analysis of electric power generation from Peshawar city MSW.

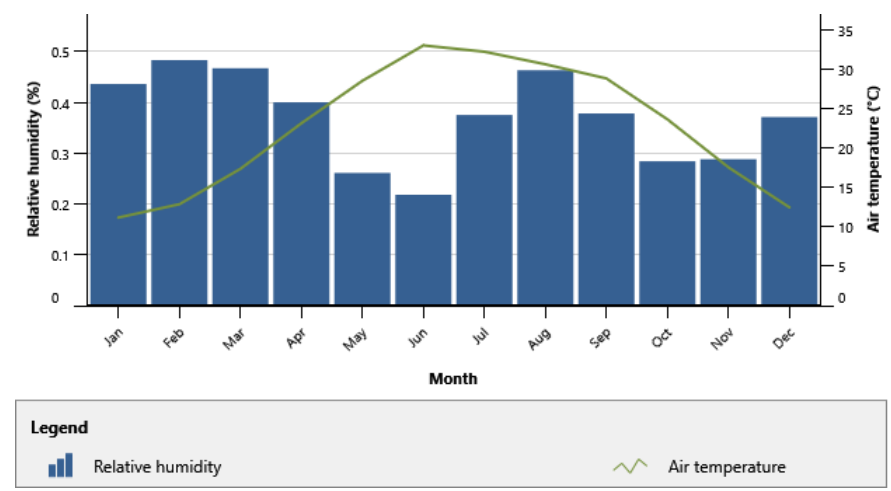

Figure 3.Peshawar city study area Climatic conditions

\section{b) Survey and data gathering}

In order to assess and direct about waste to energy plant, Composition of solid waste, the location of dumping grounds, waste to energy locality site selection, data from department of Tehsil Municipal Administration (TMA) Water and Sanitation Services Peshawar (WSSP), Local Governments has been gathered as much was possible.

\section{c) Studying different methods for energy recovery from municipal solid waste}

There are different Waste to energy plants operating around the world As in literature depicted that various methods for conversion of MSW to electricity generation i.e. Incineration, 
anaerobic digestion, pyrolysis, gasification and landfill gas to energy the type of technology selection greatly depends as it varies on the basis of the content it contained, type of solid waste, its economics and MSW processing capacity so based on the Peshawar region as it contained Mix of organic and inorganic fraction in combined as no proper solid waste management exists in the city and it also it get varies. Based upon the practices exists for waste to energy control incineration is considered to be one of the main techniques where the steam turbine is operating, along with the other reduce, reuse and recycle concept and RDF technologies can also be used as the solid waste also contain major fraction too of plastics waste.

\section{d) Prefeasibility analysis through RETScreen}

The RETScreen modeling tool is used for the Prefeasibility analysis of the waste to energy generation from MSW of Peshawar city.

The ministry of natural resources Canada has developed clean energy management software called RETScreen Expert which provides Cost-effective and time-saving techniques to find the prefeasibility and feasibility analysis of any clean and green energy project rather than custom based conventional methods. The tool is used to assess the energy production of various renewables and clean energy technologies projects and it's used to find the integrated financial analysis of the project, Greenhouse gas emission reductions, different cash flows, sensitivity, and risk analysis. [14]. The concept of analysis in RETScreen Expert software workflow in the following manners as provided which contains the different parameters for the execution of any analysis type.

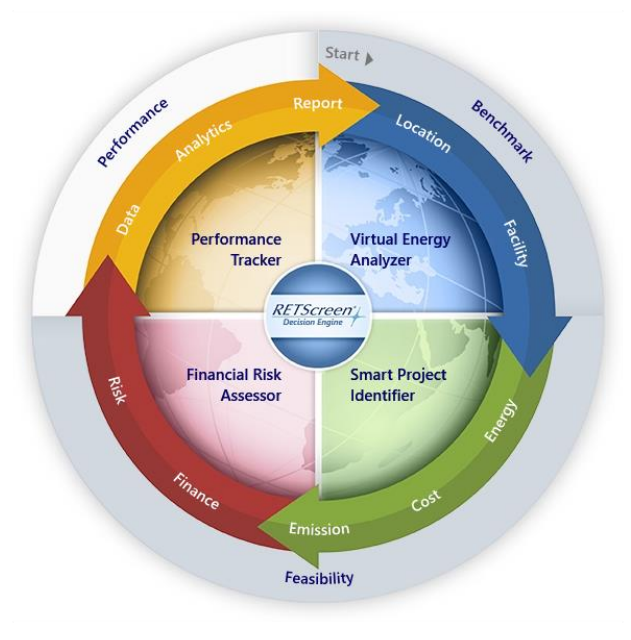

Figure 4: RETScreen analysis tool process cycle

\section{V.RESULTS AND DISCUSSION}

RETScreen Expert as a decision support tool has been used to determine the prefeasibility analysis for a $10 \mathrm{MW}$ power plant from the municipal solid waste of Peshawar city hence for the sake an analysis has been undertaken for the set up that either it is economically and environmentally viable or not.

\section{1) Power plant type selection}

Energy generation from Municipal solid waste is usually carried out using a steam turbine generator. Peshawar city MSW is a mix mixture of organic and inorganic content hence a detail prefeasibility analysis is carried out for a $10 \mathrm{MW}$ capacity unit which will generate $74,816 \mathrm{MWh}$ of electricity and fuel consumption is probably 63,707 tonnes.

\section{2) Benchmark analysis}

Benchmark analysis in RETScreen software is to make a comparative analysis of the proposed technology with base case technology in order to compare their energy performance, cost of a facility, GHG emissions, etc. These specific values of benchmark usually develop from the database of the software and clarify the view as an assumption of energy scenario, costs for the facility and GHG emissions and then after assuming benchmark values the most important then to estimate the performance and feasibility analysis, financial analysis, costs and revenue generated, greenhouse gas minimizations these can, later on, be updated as long as the data as an input obtained. In our case as a benchmark two types of the technology being selected by software using steam turbine i.e. one with fuel as coal and the other having MSW as a fuel and the benchmark unit appropriated as $0.22 \mathrm{CAD} / \mathrm{KWh}$.

\section{TABLE II: BENCHMARK ANALYSIS}

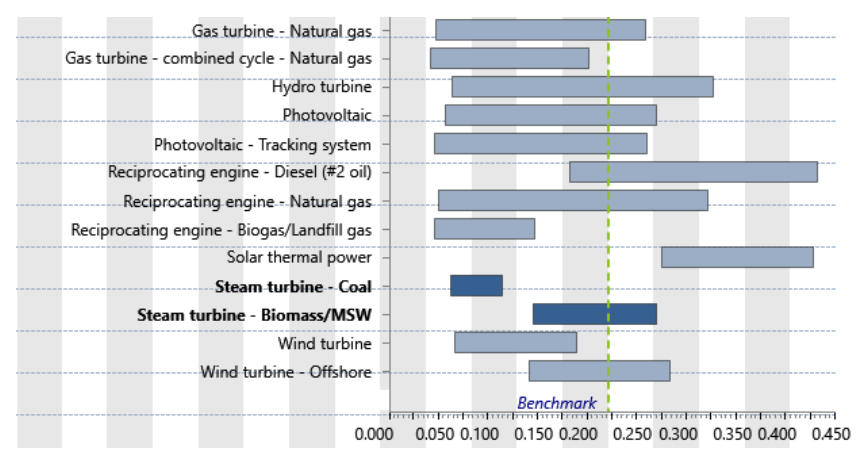

3) GHG emission reduction

The greenhouses gas mitigation by using proposed clean energy technology instead of conventional energy resources can be estimated from the emission analysis worksheet. In our study as we see that there are two cases i.e. one is the base case and other is the proposed case where there is a clear depiction that a huge quantity of GHG emission can be reduced using the proposed case in a base case the GHG emission is 37,326 tCO2 and can be minimized to a level in a proposed case to the extent is 4728.6t $\mathrm{CO} 2$ hence the annual greenhouses gas (GHG) emission reduction potential is 32,598.1 tons of $\mathrm{CO} 2$ which is as equivalent to 75809.5 barrels of crude oils being not consumed. The RETScreen provides a good platform to estimates how much greenhouses gases emission reduction cab be lessen if a clean energy being utilized instead of any conventional of fossil fuels based technology.it good compares in different format that is that much $\mathrm{C} 02$ can be reduced if number of cars and truck not to be used in transportation or that 
much of barrel of oils can be saved if that clean energy being used so it's a good foundation to estimate any green energy with various conventional technologies.

TABLE III. GHG EMISSIONS REDUCTION ANALYSIS

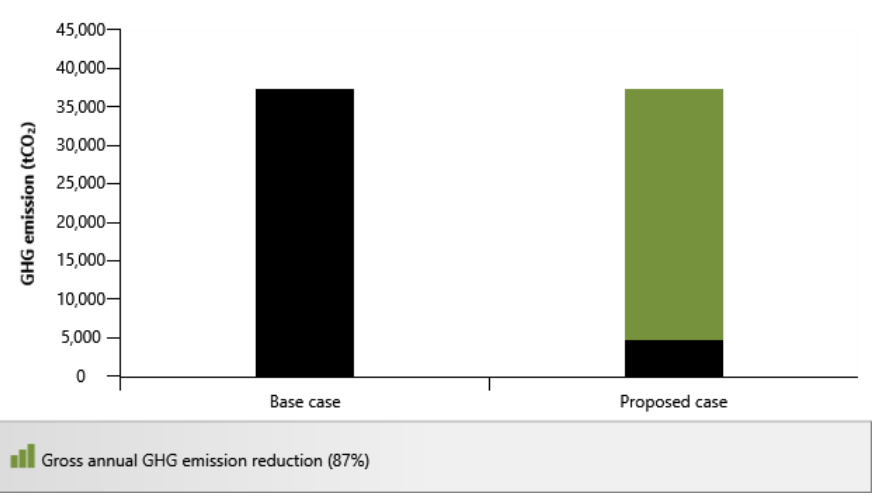

\section{4) Financial analysis of the project}

RETScreen decision support is one of the preliminary supportive tools in determining the financial analysis of any clean and green energy project hence it paves the way for investors or policymakers to proceed further with it or not. Different financial parameters as input exists from user input such as debt ratio, discount ratio, etc. and in return the software calculate internal rate of return IRR, net present value NPV, simple payback periods which allows the planners to have an overview of various financial parameters with great ease A description of these items relevance to the preliminary feasibility analysis, is included below. The fuel escalation rates are determined from current values of inflation rates as it gets varies in different range so Its opted an average of it is $9 \%$. Discount rates are provided as being followed the range from various studies and NEPRA upfront tariff and the project life for such a project is usually considered for 25 years. Clean energy projects are usually majorly by government i.e. the government provides interest-free loan in the range of $40-70 \%$ so in our case its green project hence its opted to be $70 \%$ and debt interest can be taken either zero as it interests free or in a range of $5-7 \%$.

The different costs associated with it and the revenue that can be generated from the project is evaluated hence the parameters are not fixed as it gets vary the value should be varied as long as an optimum result are obtained and following the rules and regulation for the relevant energy projects is determined by each country.
TABLE IV. FINANCIAL VIABILITY ANALYSIS

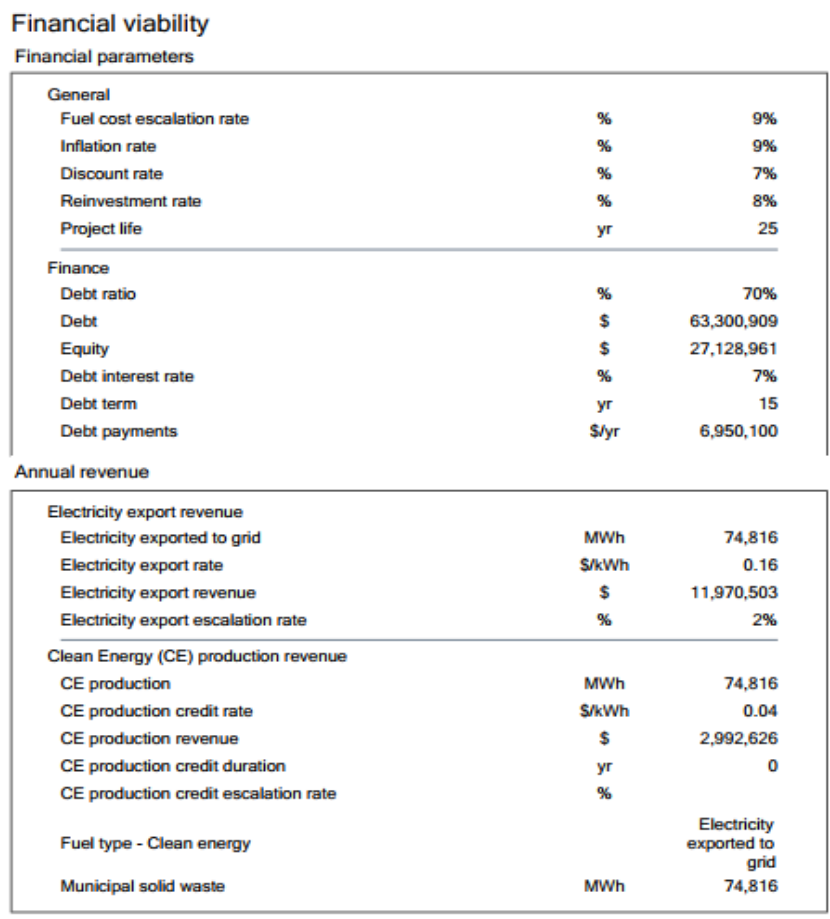

\section{CONCLUSION}

The Peshawar city MSW is increasing day by day due to huge urbanization in the city which poses serious health issues to the public, environment, soil and water contamination. Therefore, building a new WTE plant in Peshawar city is necessary in order to cope up with growing solid waste management and the energy crisis, is an urgent task for the local government. With incentives and support provided by the national government, waste to energy technologies exists in the world while the technology is usually based on the type of waste and moisture contents it contains hence from the literature studies steam turbine systems used for waste to energy projects Peshawar city generates almost 1000 ton/day hence for the first analysis base a $10 \mathrm{MW}$ power plant set up is proposed in this study which yields a good amount of electricity and mitigates the potential greenhouse gases due to the high moisture and low heating value of MSW in Peshawar city a steam turbine generation unit has been proposed which will fetch to both the government and private investors a high financial benefit ultimately will consequence in several environmental benefits for the city of Peshawar.

\section{REFERENCES}

[1] A. Kumar and S. R. Samadder, "A review on technological options of waste to energy for effective management of municipal solid waste," Waste Manag., vol. 69, pp. 407-422, 2017

[2] P. Hoornweg, Daniel, Bhada-Tata, "What a waste - a global review on solid waste," vol. 1, no. 5, p. 116, 2012.

[3] D. Moya, C. Aldás, D. Jaramillo, E. Játiva, and P. Kaparaju "ScienceDirect ScienceDirect Waste-To-Energy Technologies: an opportunity of energy recovery from Municipal Solid Waste, using Quito - Ecuador as case study," Energy Procedia, vol. 134, pp. 327-336, 2017 
[4] S. Aatif and M. Naeem Arbab, "Capacity Estimation of Power Generation from MSW of Peshawar City," Int. J. Comput. Appl., vol. 111 , no. 15 , pp. $40-45,2015$.

[5] M. J. S. Zuberi and S. F. Ali, "Greenhouse effect reduction by recovering energy from waste landfills in Pakistan," Renew. Sustain. Energy Rev., vol. 44, pp. 117-131, 2015.

[6] C. E. Palacio et al., "Municipal Solid Waste Management and Energy Recovery José."

[7] D. Moya, C. Aldás, G. López, and P. Kaparaju, "Municipal solid waste as a valuable renewable energy resource: A worldwide opportunity of energy recovery by using Waste-To-Energy Technologies," in Energy Procedia, 2017.

[8] International Renewable Energy Agency (IRENA), 2016. Renewable EnergyStatistics.

[9] <http://www.irena.org/DocumentDownloads/Publications/IRENA_RE Statistics_2016.pdf> (accessed 21.03.2017).

[10] World Energy Council, "World Energy Resources 2016," World Energy Counc. 2016, pp. 6-46, 2016.

[11] G. Ali and N. A. Molla, "Selection of Appropriate Technology for Solid Waste Management: A Case of Thammasat Hospital, Thailand. Himalayan Adaptation, Water and Resilience (HI-AWARE) Research View project Climate change policies in Asia View project," no. April, 2010.

[12] S. T. Tan, W. S. Ho, H. Hashim, C. T. Lee, M. R. Taib, and C. S. Ho, "Energy, economic and environmental (3E) analysis of waste-to-energy (WTE) strategies for municipal solid waste (MSW) management in Malaysia," Energy Convers. Manag., vol. 102, pp. 111-120, 2015.

[13] K. A. Kalyani and K. K. Pandey, "Waste to energy status in India: A short review," Renew. Sustain. Energy Rev., vol. 31, pp. 113-120, 2014.

[14] R. Intharathirat and P. Abdul Salam, "Valorization of MSW-to-Energy in Thailand: Status, Challenges and Prospects," Waste and Biomass Valorization, vol. 7, no. 1, pp. 31-57, 2016.

[15] D. Moya, J. Paredes, and P. Kaparaju, "Technical, financial , economic and environmental pre-feasibility study of geothermal power plants by RETScreen - Ecuador's case study," Renew. Sustain. Energy Rev., vol. 92, no. December 2017, pp. 628-637, 2018. 